\title{
THE EFFECT OF TOPICAL CORTICOSTEROIDS ON REFRACTION AND CORNEAL HAZE FOLLOWING EXCIMER LASER TREATMENT OF MYOPIA: AN UPDATE. A PROSPECTIVE, RANDOMISED, DOUBLE-MASKED STUDY
}

\author{
D. S. GARTRY ${ }^{1}$, MALCOLM G. KERR MUIR ${ }^{2}$ and J. MARSHALL ${ }^{3}$ \\ London
}

\begin{abstract}
SUMMARY
Several thousands of myopic patients have undergone photorefractive keratectomy (PRK) worldwide (prior to the publication of long-term, carefully controlled studies). The evidence in support of the currently widespread use of topical corticosteroids after PRK, however, is limited. We report the results of a prospective, doublemasked trial to determine the effect of dexamethasone $0.1 \%$ on refraction and anterior stromal haze following -3.00 and -6.00 dioptre PRK procedures $(n=113$; minimum follow-up 1 year). Initially the reduction in myopia was significantly greater in the steroid group compared with the placebo group $(p<0.002)$. However, on discontinuing the corticosteroids at 3 months this difference became statistically insignificant $(p>0.2)$. There was no statistically significant effect on anterior stromal haze at any stage. We conclude that, in view of their side effects, it would be unacceptable to use topical corticosteroids in the long term to maintain the initial beneficial effect on refraction. We therefore consider that topical corticosteroids should not be used following PRK.
\end{abstract}

Following laboratory, animal and blind eye studies in several centres, photorefractive keratectomy (PRK) with the argon fluoride excimer laser has been used increasingly around the world over the past 3 years for the treatment of simple myopia. The interaction of excimer laser radiation with the corneal surface (photoablation) results in highly precise removal of tissue. By interposing a computercontrolled iris diaphragm in the beam a graded exposure can be achieved and the central cornea flattened to effect a reduction of myopia. However, the precision with which

From: Department of Ophthalmology, St. Thomas' Hospital, London. 'Senior Registrar, Moorfields Eye Hospital, London; ${ }^{2}$ Consultant Ophthalmologist, St. Thomas' Hospital, London; ${ }^{3}$ Scientific Director, St. Thomas' Hospital, London, UK.

Correspondence to: David S. Gartry, FRCS, FCOphth, Moorfields Eye Hospital, City Road, London EC1V 2PD, UK. the corneal surface can be reprofiled has been shown to be overshadowed by the individual variation in wound healing, which results in a variable degree of loss of corneal transparency (haze) and regression of the induced refractive change. ${ }^{1,2}$ Since the individual variation increases with depth of ablation, ${ }^{2}$ predictability has been described as only 'fair' for low degrees of myopia. ${ }^{2}$ Anterior stromal haze and loss of refractive correction have both been shown to be correlated with depth of ablation ${ }^{3}$ and therefore in order to improve predictability and limit side effects the wound healing response following excimer laser PRK must be modulated. Currently there is considerable interest in pharmacological manipulation of this response.

In an earlier paper we discussed the evidence in support of topical corticosteroids in the treatment of corneal injuries including incisions. ${ }^{3}$ The superficial wide area excisions which result from excimer laser photoablation, however, are very different from the wounds encountered clinically or those used in laboratory models when investigating the role of these agents. In addition, there is only limited evidence from one study using a rabbit model that topical corticosteroids might have a beneficial effect on corneal haze, and no animal data to suggest that there might be an effect on refractive outcome. ${ }^{4}$ In spite of this limited evidence in support of topical corticosteroids all groups investigating PRK in sighted eyes have used a steroid regimen. ${ }^{1,2,5-9}$ There has also been a suggestion that the frequency of administration of these drops can be titrated against the post-operative progress of both anterior stromal haze and rate of regression. ${ }^{5,6}$ In addition, there is considerable variation in treatment parameters and post-operative regimens from centre to centre as highlighted in our previous paper. ${ }^{3}$

We demonstrated that corneal clarity can be improved in a number of superficial pathologies and none of these 
patients received steroids. ${ }^{10}$ In addition, in our blind eye PRK series -7.00 dioptre (D) ablations were performed (on axis ablation depth of $44 \mu \mathrm{m}$ ) and no corticosteroids were used. ${ }^{1}$ Average haze was noted to be less than that seen in our original sighted eye cohort $(n=120$, follow-up 2 years $)^{1,2}$ although mean age was greater in the blind eye series. Ethics committee constraints based on current clinical experience of corneal wound healing and the above animal study led to all patients in the original sighted eye cohort receiving high-dose topical corticosteroids. In spite of this, considerable haze, regression and individual variation were reported. ${ }^{1,2}$ In addition, 21 patients from the original cohort defaulted on the corticosteroid regimen and there was no discernible difference in either haze or regression between this group and the main body of the cohort.

In view of the limited evidence in support of corticosteroids post-PRK, the individual variation and the likelihood of side effects with these agents, we designed a prospective, randomised, age-matched, double-masked trial to address the question: Do topical corticosteroids influence haze or refraction post-PRK? We reported the results of the 6-month follow-up of this trial in which it was found that topical corticosteroids had a significant beneficial effect on refraction while administered but that this effect became statistically insignificant when steroids were discontinued. ${ }^{3}$ This paper reports the 1-year follow-up of the same cohort.

\section{MATERIALS AND METHODS}

\section{Patient Selection}

Following ethics committee approval, prospective patients were sent background information and a questionnaire. The selection criteria have been described previously and are summarised in Table $\mathrm{I} .{ }^{3}$ To minimise variation between patients resulting from a variety of attempted corrections we planned to perform only $-3.00 \mathrm{D}$ and $-6.00 \mathrm{D}$ corrections (ablation depths 25 and $44 \mu \mathrm{m}$ respectively). This also allowed investigation of the effects of topical dexamethasone $0.1 \%$ at two discrete ablation depths. We therefore selected patients with preoperative refraction close to $-3.00 \mathrm{D}(-2.88 \mathrm{D} \pm 0.37 \mathrm{D})$ and $-6.00 \mathrm{D}(-5.96 \mathrm{D} \pm 0.53 \mathrm{D})$. Emmetropia was not, therefore, the aim in every case. Sample size for statistical significance was calculated using the variance of the data from our original cohort of 120 patients: ${ }^{1,2}$

1. Refraction. The accuracy of refraction was assumed to be of the order of $\pm 0.50 \mathrm{D}$. In the $-3.00 \mathrm{D}$ group we considered that a $1.00 \mathrm{D}$ difference between placebo and steroid groups would be regarded as clinically significant, and a $2.00 \mathrm{D}$ difference in the $-6.00 \mathrm{D}$ group.

2. Haze. Given the difficulty in assessing haze subjectively, ${ }^{1-3}$ we considered that a $1+$ difference between groups would be clinically significant.

The minimum total sample sizes required (calculated to give the standard $80 \%$ chance of detecting a difference at the 5\% significance level) were therefore $n=36$ for the $-3.00 \mathrm{D}$ group and $n=50$ for the $-6.00 \mathrm{D}$ group.

\section{Age and Sex}

In the $-3.00 \mathrm{D}$ group $(n=57)$ the mean age was 35.51 years, SD 8.1 (range 24-58 years). The male to female (M:F) ratio was 23:34.

In the $-6.00 \mathrm{D}$ group $(n=56)$ the mean age was 39.6 years, SD 9.87 (range 24-66 years). The M:F ratio was 21:35.

\section{Pre-operative Assessment}

The details of the pre-operative assessment have been reported previously. Briefly, this comprised general ophthalmic examination, subjective refraction, variable contrast visual acuity assessment and ultrasonic axial length measurement. The .113 patients recruited into the study were coded and placed in 'steroid' or 'placebo' groups by random, age-matched allocation. The final numbers in each group were:

Group A ( $-3.00 \mathrm{D}$ steroid group): $n=29$, mean pre-operative refraction $=-2.94 \mathrm{D}(\mathrm{SD}=0.38 \mathrm{D}$, range $-2.125 \mathrm{D}$ to $-3.625 \mathrm{D})$.

Group B (-3.00D placebo group): $n=28$, mean preoperative refraction $=-2.82 \mathrm{D} \quad(\mathrm{SD}=0.36 \mathrm{D}$, range $-2.25 \mathrm{D}$ to $-3.50 \mathrm{D})$.

Group C (-6.00D steroid group): $n=28$, mean pre-operative refraction $=-5.90 \mathrm{D}(\mathrm{SD}=0.54 \mathrm{D}$, range $-5.00 \mathrm{D}$ to $-7.00 \mathrm{D})$.

Group D (-6.00D placebo group): $n=28$, mean preoperative refraction $=-6.02 \mathrm{D} \quad(\mathrm{SD}=0.51 \mathrm{D}$, range $-4.75 \mathrm{D}$ to $-7.00 \mathrm{D})$.

\section{The Choice of Topical Corticosteroid}

The placebo and steroid preparations were identical in every respect except for the presence or absence of dexamethasone $0.1 \%$. This steroid was chosen for its proven therapeutic efficacy and ability to penetrate the cornea readily. ${ }^{11-13}$ To achieve an appearance, taste and $\mathrm{pH}$ identical to the placebo a buffered solution of the metasul-

Table I. Patient selection criteria

\begin{tabular}{|c|c|}
\hline Parameter & Criterion \\
\hline Refraction & $\begin{array}{l}\text { Myopes with stable refraction close to }-3.00 \mathrm{D} \\
\text { or }-6.00 \mathrm{D}\end{array}$ \\
\hline Astigmatism & Less than $1.00 \mathrm{DC}$ \\
\hline Visual acuity & $\begin{array}{l}\text { Best corrected visual acuity } 20 / 30 \text { or greater in } \\
\text { both eyes }\end{array}$ \\
\hline Age & Lower limit 24 years \\
\hline Contact lens history & $\begin{array}{l}\text { Contact lens wearers preferred due to likelihood } \\
\text { of induced anisometropia (mainly soft lens } \\
\text { wearers enlisted). Patients with evidence of } \\
\text { fluctuating refraction due to corneal distortion } \\
\text { excluded }\end{array}$ \\
\hline Ophthalmic history & $\begin{array}{l}\text { Patients with a history of ocular disease or } \\
\text { surgery excluded }\end{array}$ \\
\hline Occupation & $\begin{array}{l}\text { Individuals with exacting vocational visual } \\
\text { requirements excluded (e.g. pilots, professional } \\
\text { drivers) }\end{array}$ \\
\hline Motivation & $\begin{array}{l}\text { Prospective patients asked to state their reasons } \\
\text { for wishing to be included in the trial. Only } \\
\text { those with realistic expectations included }\end{array}$ \\
\hline
\end{tabular}


phobenzoate salt was used. Thiomersal $0.005 \%$ was present in both placebo and steroid preparations.

\section{Corticosteroid Regimen}

The corticosteroid regimen was $\times 5$ per day for 2 months, $\times 4$ per day for 2 weeks, $\times 3$ per day for 1 week, twice per day for 1 week, once per day for 1 week then discontinued. All patients were counselled at great length regarding the aims of the trial and the importance of compliance.

\section{The Procedure}

A Summit Technology UV200 excimer laser was used with an emission wavelength of $193 \mathrm{~nm}$, a fixed pulse repetition rate of $10 \mathrm{~Hz}$ and a radiant exposure of $180 \mathrm{~mJ} / \mathrm{cm}^{2}$ at the cornea. There was no effluent removal and no eye stabilising system. The laser, which had been serviced immediately prior to the trial, was calibrated at the beginning of each day and printouts were obtained at the beginning, middle and end of each session (to confirm energy output). As many treatment parameters as possible were kept constant, including the ablation rate $(0.22 \mu \mathrm{m}$ per pulse) and the maximum beam diameter $(4 \mathrm{~mm})$. A detailed consent form was signed prior to the procedure. Patients were allocated randomly to one of the two surgeons (D.S.G., M.G.K.M.), both of whom used a standardised surgical technique as described previously. ${ }^{1-3}$ Patients were required to fixate a target light within the laser aperture for the duration of the procedure; this was 10 seconds and 17 seconds for $-3.00 \mathrm{D}$ and $-6.00 \mathrm{D}$ corrections respectively. To ensure uniformity of treatment parameters and ease of follow-up all 113 patients were treated in a 2-week period (July 1991).

\section{Post-operative Management/Monitoring}

The treatment regimen immediately post-procedure was identical in each case and comprised oral analgesics, mydriasis and Oc chloramphenicol $1 \%$ and pad. Administration of the study drops commenced the following day when the pad was removed, and neither the surgeon nor the patient knew which trial drops were being instilled. The study was therefore 'double-masked'. The post-operative follow-up schedule has been described in detail elsewhere. $^{3}$

\section{RESULTS}

From our previous studies ${ }^{1,2}$ we noted that stabilisation of refraction occurred after 3-4 months and that anterior stromal haze was maximal at 5-6 months. We therefore decided to break the code to determine patient assignation after the 6-month visit.

\section{Allergic Response}

Nine patients (8\%) suffered an allergic response to thiomersal and were therefore excluded from the main cohort. This reaction occurred by the second week in each case and took the form of hyperaemia, watering and lid oedema. On breaking the code all but one of these patients was found to have been using the placebo preparation.

\section{Intraocular Pressure (IOP) Increase}

A significant rise in IOP $(>5 \mathrm{mmHg}$ ) occurred in 12 patients (11\%). In 2 of these IOP was in excess of $40 \mathrm{mmHg}$; therefore the eyedrops were discontinued and these 2 patients were excluded from the trial. The maximum IOP in the remaining 10 patients, prior to the final month of treatment, was $22 \mathrm{mmHg}$ and, as the eyedrops were about to be administered in reducing doses, the regimen was completed as per the protocol. All patients with raised IOP belonged to the steroid groups.

The final number in each group was therefore:

-3.00D: $n=50$ (27 in the steroid group, 23 in the placebo group)

$-6.00 \mathrm{D}: n=52$ (27 in the steroid group, 25 in the placebo group)

\section{Refractive Outcome}

The mean change in refraction with time for the $-3.00 \mathrm{D}$ and $-6.00 \mathrm{D}$ groups up to and including the 1-year visit is shown in Fig. 1 and Table II. An initial overcorrection followed by regression to a plateau with significant undercorrection at around 3 months is common to both groups. As reported previously, in the first 3 months the mean change in refraction for the placebo groups (Fig. 1a and b, broken line) is consistently less than that of the groups using steroid. However, by the third month in the $-3.00 \mathrm{D}$ group there is no statistically significant difference between steroid and placebo $(p=0.1 ; 95 \%$ confidence interval $-0.10,1.01$ ). All data were found to be normally distributed and therefore two-tailed Student's $t$-tests were used.) By the sixth month there was no significant difference in either the $-3.00 \mathrm{D}$ or $-6.00 \mathrm{D}$ groups $(p=0.62$ and 0.2 respectively; $95 \%$ confidence intervals $-0.43,0.71$ and $-0.43,2.00$ respectively). Similarly, at 1 year no significant difference could be demonstrated between the two groups in spite of a $0.28 \mathrm{D}$ difference between the means in the $-3.00 \mathrm{D}$ group and a $0.78 \mathrm{D}$ difference in the $-6.00 \mathrm{D}$ group ( $p=0.45$ and 0.2 respectively; $95 \%$ confidence intervals $-0.40,0.70$ and $-0.38,1.96$ respectively). There was no statistically significant difference in mean change in refraction between the third, sixth and twelfth months in either group. In order to demonstrate the individual variation encountered all data points at 1-year follow-up are represented on a scattergram (Fig. 2).

\section{Anterior Stromal Haze}

The time course for the development of anterior stromal haze, as assessed subjectively on slit lamp examination, is shown in Fig. 3. In the -3.00D groups, with and without steroids, haze appears to be maximal at around 3 months, while in the $-6.00 \mathrm{D}$ group haze is maximal at 5-6 months. As reported previously, there was no statistically significant difference in haze between the steroid and placebo groups at any stage (all $p$ values $>0.05$ ). The same is true of the 1-year data. A downward trend is seen for both groups in which anterior stromal haze reduces between the sixth and twelfth months. The mean subjective haze grad- 


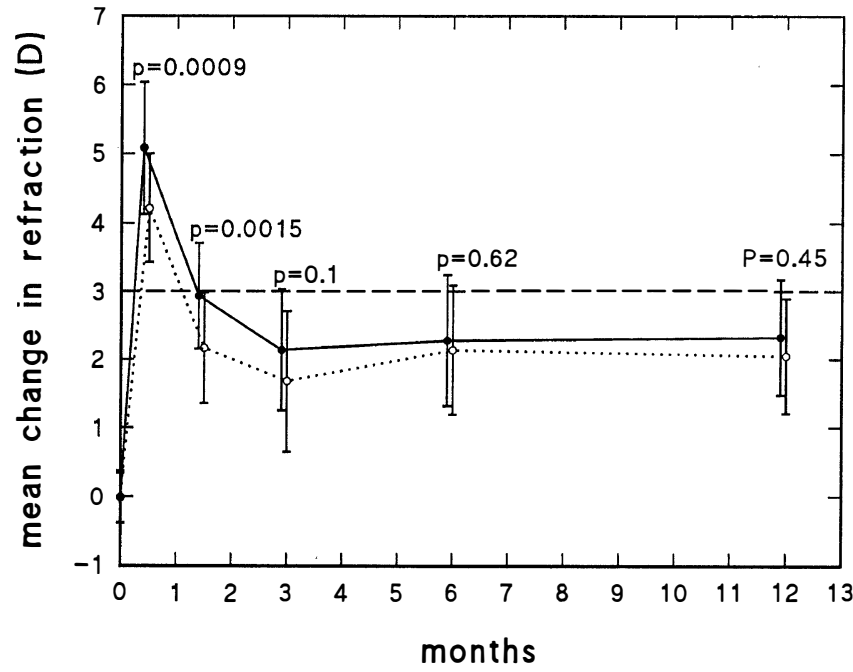

Fig. 1 .

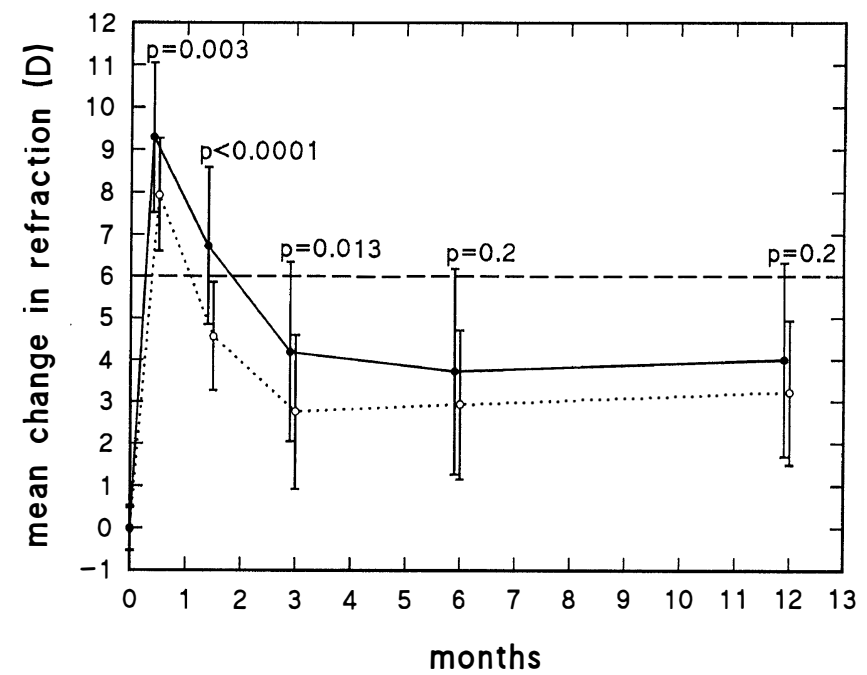

Fig. 1b.

Fig. 1. Mean change in refraction with time following $-3.00 \mathrm{D}(\mathrm{a})$ and $-6.00 \mathrm{D}(\mathrm{b})$ photorefractive keratectomy $(P R K)$. Filled circles and continuous line, corticosteroid; open circles and broken line, placebo. Data points are displaced slightly in time to facilitate comparison of error bars $( \pm 1 S D) .(p<0.05=$ a statistically significant difference. $)$

ing at 12 months in the $-3.00 \mathrm{D}$ group is 0.5 while for the $-6.00 \mathrm{D}$ group the value is 0.74 . Having used two discrete ablation depths it is possible also to demonstrate that the amount of haze is highly statistically significantly greater in the $-6.00 \mathrm{D}$ group.

\section{Axial Length}

As reported previously, there was no correlation between axial length and either change in refraction or subjective haze grading.

\section{Complications}

Complications are listed in Table III. The number of patients demonstrating a loss of best spectacle corrected visual acuity in each of the four subgroups (-3.00D placebo and steroid, $-6.00 \mathrm{D}$ placebo and steroid) is small and no significant difference between these groups could be demonstrated in terms of this loss. The change in best spectacle corrected Snellen visual acuity (100\% contrast) is shown in Fig. 4 for both the 6-month and 12-month visits. At 6 months $20 \%$ of individuals had lost one or more lines of Snellen acuity and one individual had lost three lines (anterior stromal haze is maximal at around this stage). Eighteen per cent lost half a line while the visual acuity of $41 \%$ remained unchanged. Twenty-three per cent gained between a half and one line, presumably due to increased retinal image size (Fig. 4a). At the 1-year stage best corrected spectacle acuity had improved in some of those individuals who had experienced a reduction at the 6-month stage. Fifteen per cent lost between one and two lines and no patient lost more than two lines. Interestingly, only $6 \%$ showed an improvement of half a line and $5 \%$ of one line (Fig. 4b).

\section{DISCUSSION}

At this relatively early stage in the clinical application of excimer laser photoablation it can not be assumed that topical corticosteroids can be used successfully to modify wound healing following PRK. Experimental evidence for this assumption is limited. ${ }^{4}$ Previous phototherapeutic keratectomy (PTK) and blind eye studies have indicated that where topical corticosteroids are not administered the degree of haze encountered is not significantly greater than that seen in sighted eye PRK trials in which steroids are used in all patients. ${ }^{1,2,7-10}$ Where individuals have defaulted there has been no apparent detrimental effect on either refractive outcome or anterior stromal haze. ${ }^{1,2}$

Table II. Mean change in refraction (D) with time following $-3.00 \mathrm{D}$ and $-6.00 \mathrm{D}$ PRK: Comparison of placebo and steroid groups

\begin{tabular}{|c|c|c|c|c|c|c|}
\hline \multirow[b]{2}{*}{ Treatment group } & \multirow[b]{2}{*}{ Pre-operative } & \multicolumn{5}{|c|}{ Follow-up interval } \\
\hline & & $2 / 52$ & $6 / 52$ & $3 / 12$ & $6 / 12$ & 1 year \\
\hline$-3.00 \mathrm{D}$ placebo & $\begin{array}{c}-2.82 \\
(0.36)\end{array}$ & $\begin{array}{c}4.21 \\
(0.79)\end{array}$ & $\begin{array}{c}2.17 \\
(0.82)\end{array}$ & $\begin{array}{c}1.68 \\
(1.03)\end{array}$ & $\begin{array}{c}2.14 \\
(0.95)\end{array}$ & $\begin{array}{c}2.05 \\
(0.84)\end{array}$ \\
\hline$-3.00 \mathrm{D}$ steroid & $\begin{array}{c}-2.94 \\
(0.38)\end{array}$ & $\begin{array}{c}5.08 \\
(0.95)\end{array}$ & $\begin{array}{c}2.93 \\
(0.77)\end{array}$ & $\begin{array}{c}2.14 \\
(0.89)\end{array}$ & $\begin{array}{c}2.28 \\
(0.96)\end{array}$ & $\begin{array}{c}2.33 \\
(0.85)\end{array}$ \\
\hline$-6.00 \mathrm{D}$ placebo & $\begin{array}{c}-6.02 \\
(0.51)\end{array}$ & $\begin{array}{c}7.93 \\
(1.33)\end{array}$ & $\begin{array}{c}4.56 \\
(1.29)\end{array}$ & $\begin{array}{c}2.76 \\
(1.83)\end{array}$ & $\begin{array}{c}2.93 \\
(1.78)\end{array}$ & $\begin{array}{c}3.22 \\
(1.72)\end{array}$ \\
\hline$-6.00 \mathrm{D}$ steroid & $\begin{array}{l}-5.90 \\
(0.54)\end{array}$ & $\begin{array}{c}9.29 \\
(1.77)\end{array}$ & $\begin{array}{c}6.72 \\
(1.87)\end{array}$ & $\begin{array}{c}4.19 \\
(2.14)\end{array}$ & $\begin{array}{c}3.72 \\
(2.45)\end{array}$ & $\begin{array}{r}4.00 \\
(2.31)\end{array}$ \\
\hline
\end{tabular}

Values in parentheses are standard deviations. 


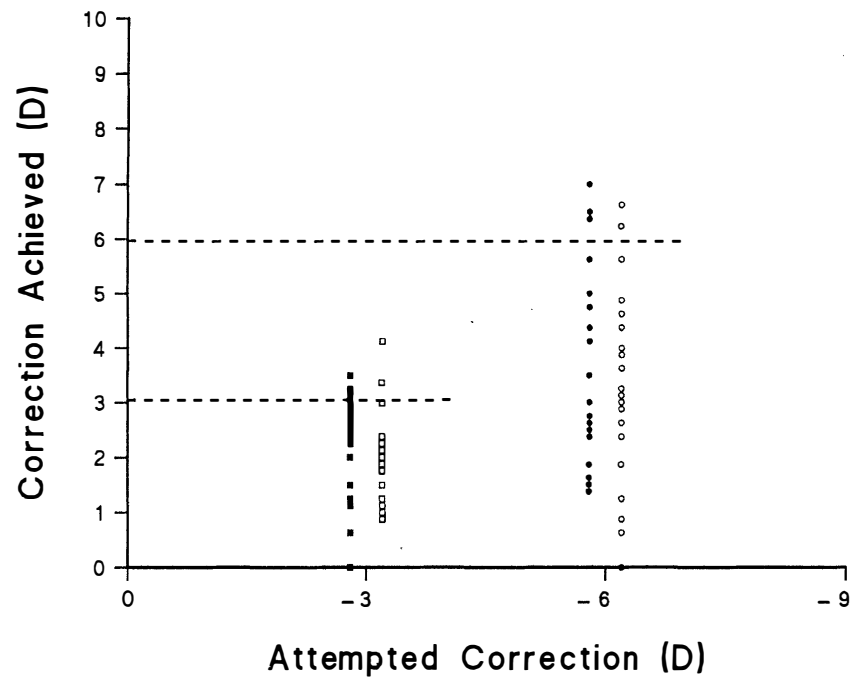

Fig. 2. Individual variation following PRK (all groups) at 1 year. A wide spread of data points is demonstrated. Some individuals in each group have regressed back to their preoperative refraction. Data points are displaced slightly in time to facilitate comparison of groups. Filled symbols, steroid groups; open symbols, placebo groups.

Because of the widespread use of the procedure and the considerable individual variation seen in the wound healing response following $\mathrm{PRK}^{1-3}$ it is important to ascertain whether corticosteroids have a significant effect on refraction, anterior stromal haze and other complications.

\section{Refractive Outcome}

As reported previously, the mean change in refraction was statistically significantly greater in the corticosteroid group (i.e. corticosteroids have a beneficial effect on refraction) in the first 3 months after PRK (Fig. 1, Table II). In the $-3.00 \mathrm{D}$ group no statistically significant difference in refraction was found beyond (and including) the 3 -month stage. In the $-6.00 \mathrm{D}$ group a statistically significant difference exists up to 3 months but this significance

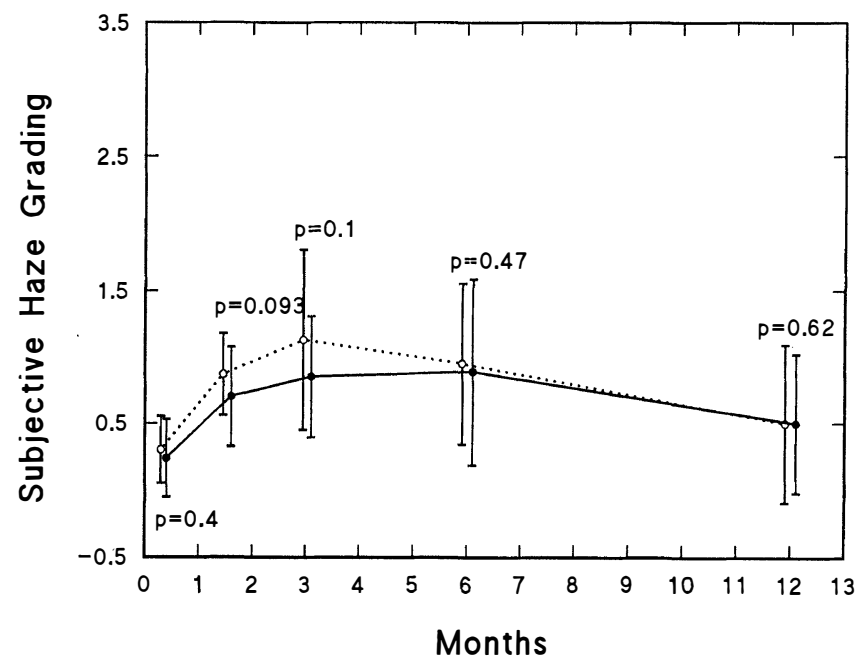

Fig. 3a. is lost by 6 months. At the 1-year stage dexamethasone had been discontinued for 9 months and no statistically significant difference between placebo and corticosteroid groups was demonstrated. This would indicate that if corticosteroids have an effect it is sustained only during their administration. The difference between the mean change in refraction comparing steroid with placebo groups at 1 year is $0.28 \mathrm{D}(-3.00 \mathrm{D}$ group) and $0.78 \mathrm{D}$ (-6.00D group). While these differences, particularly in the $-6.00 \mathrm{D}$ group, would seem to be beneficial they are not statistically significant.

If topical corticosteroids can be used to reduce cellular activity (either epithelial hyperplasia or collagen synthesis) then it would be expected that their effects will be maximal in the first few post-operative months when there is marked stromal remodelling and maximal keratocyte activity. Once this initial healing phase is over it might be expected that beneficial effects from steroid administration would be sustained, since in all histopathological studies stromal changes beyond this period are small. ${ }^{14-17}$ In contrast, any corticosteroid effect after the first 3 months would not be due to large-scale collagen remodelling but might be related to direct effects on epithelial cells or hydration of the stroma. Anecdotal reports from centres using flexible corticosteroid regimens in the first 6 postoperative months suggest that regression can be reversed and anterior stromal haze reduced by increasing the dose or reinstating treatment with topical steroids (Seiler and Ten groth, personal communication).

These findings are not at odds with the results of the present study since we have demonstrated a statistically significant beneficial effect on refraction while topical steroids are used in the first few months after PRK. Because of possible side effects ${ }^{18-20}$ the present study was not designed to investigate the effect of long-term regular use of topical corticosteroids. It is therefore not possible to comment on the likely outcome had these agents been continued in high doses beyond the 3-month stage. If the

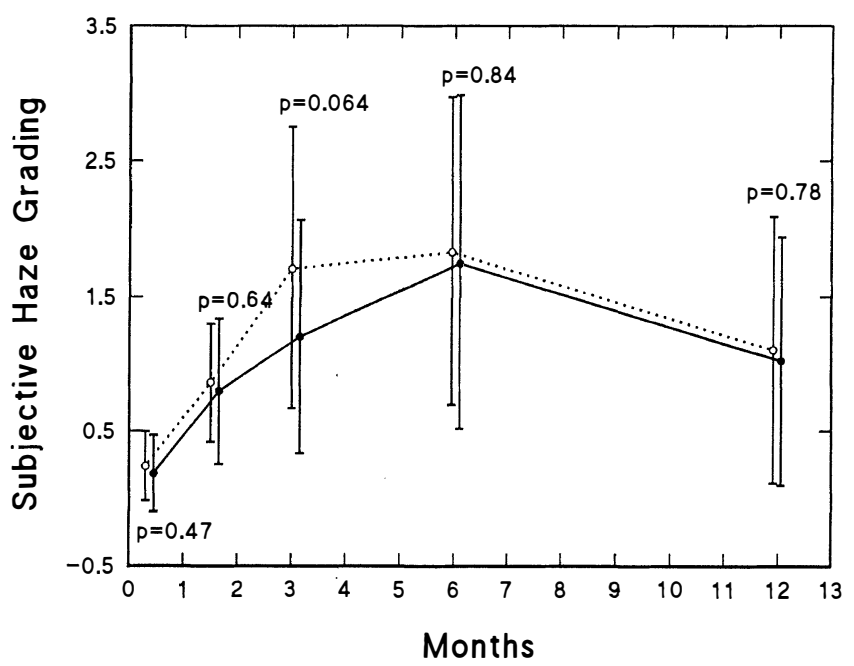

Fig. 3b.

Fig. 3. Mean subjective haze grading with time following $-3.00 D(a)$ and $-6.00 D(b)$ PRK. Filled circles and continuous line, corticosteroid; open circles and broken line, placebo. Data points are displaced slightly in time to facilitate comparison of error bars $( \pm 1 S D) .(p<0.05=$ a statistically significant difference. $)$ 
Table III. Complications of PRK : $\mathbf{t} 12$ months $(n=96)$

\begin{tabular}{|c|c|c|c|c|c|}
\hline \multirow[b]{2}{*}{ Complication } & \multicolumn{2}{|c|}{$-3.00 \mathrm{D}$ PRK } & \multicolumn{2}{|c|}{$-6.00 \mathrm{D}$ PRK } & \multirow{2}{*}{$\begin{array}{c}\text { Total } \% \text { of } \\
\text { patients affected }\end{array}$} \\
\hline & Steroid & Placebo & Steroid & Placebo & \\
\hline Reduced VA $(>1 \text { line })^{\mathrm{a}}$ & 3 & 4 & 8 & 7 & 15 \\
\hline Tender to touch & 7 & 4 & 4 & 8 & 16 \\
\hline Foreign body sensation & 4 & 5 & 4 & 2 & 12 \\
\hline Reduced night vision & 3 & 5 & 3 & 4 & 12 \\
\hline Significant night halo ${ }^{b}$ & 2 & 2 & 3 & 5 & 12 \\
\hline Epithelial instability & - & 1 & 1 & 1 & 3 \\
\hline Epithelial iron lines (Gartry/Kerr Muir) & 6 & 8 & 9 & 8 & 32 \\
\hline Slight ptosis & 1 & - & - & - & 1 \\
\hline VA reduced in bright light & - & - & 1 & - & 1 \\
\hline
\end{tabular}

VA, visual acuity.

${ }^{\text {a }}$ The majority of patients in this category lost between one and two lines.

${ }^{\mathrm{b}}$ Sufficient to interfere with night driving.

statistically beneficial effect seen in the first 3 months could be sustained by continued administration then the problem remains as to how long these potentially harmful agents can be used with impunity. This is of particular relevance in the context of refractive surgery where the eye is, in all other respects, healthy.

It should be noted that the same overall trend to undercorrection with considerable individual variation, as seen in our original cohort, ${ }^{1,2}$ was evident in all four groups (Figs. 1, 2). In both the $-3.00 \mathrm{D}$ and $-6.00 \mathrm{D}$ groups (with and without steroids) it can be seen that some patients have regressed to their pre-operative refraction while overcorrection is uncommon (Fig. 2).

\section{Anterior Stromal Haze}

Anterior stromal haze, assessed at the slip lamp, was found to increase to a maximum at around 3 months in the $-3.00 \mathrm{D}$ groups and at between 5 and 6 months in the $-6.00 \mathrm{D}$ groups (Fig. 3). No statistically significant difference in haze was demonstrated between the steroid and placebo groups at any stage of follow-up. The same results were obtained when objective assessment of haze (described previously ${ }^{3,21,22}$ ) was used, although the abso-

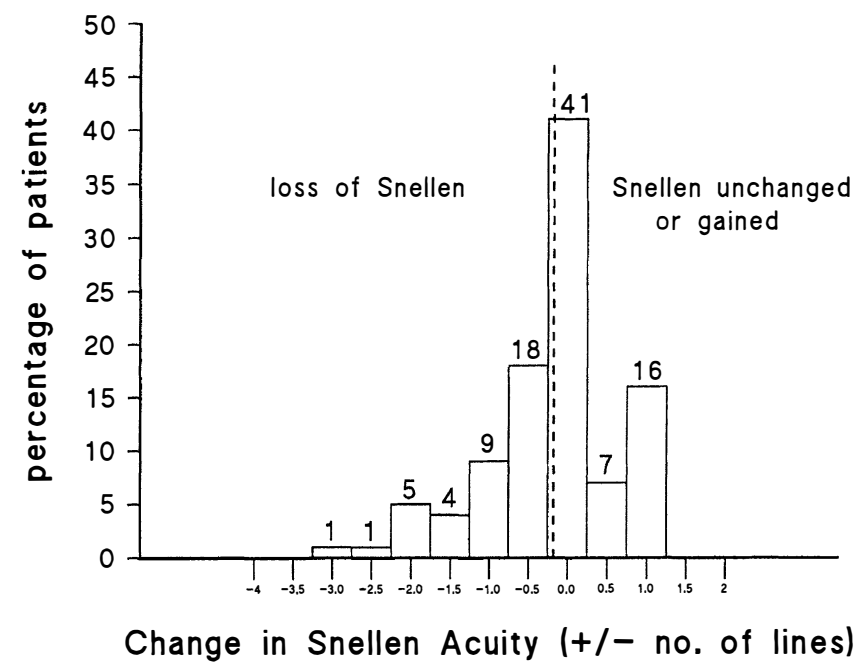

Fig. 4a. lute time course for development of haze differs slightly. Again no statistically significant difference was found between the corticosteroid and control groups. Both subjective and objective haze grading show considerable individual variation, suggesting that differences in wound healing are responsible for the spectrum of haze seen.

As previously reported, ${ }^{3}$ the amount of anterior stromal haze correlated only poorly with reduction in best spectacle corrected Snellen acuity. The number of patients who experienced a loss of Snellen acuity within each of the four groups was relatively small and precludes the application of meaningful confidence limits. It is of interest, however, that anterior stromal haze shows a downward trend from 6 months to 1 year (Fig. 3) for all groups and that in the same period there is an overall improvement in those patients who experienced a loss of best spectacle corrected visual acuity (Fig. 4). At 6 months one patient, who was in the $-6.00 \mathrm{D}$ steroid group, had lost three lines of Snellen acuity while at the 1-year stage the deficit had improved, in keeping with the general trend, to one and a half lines.

We have been able to confirm that there is a highly significant statistical correlation between anterior stromal

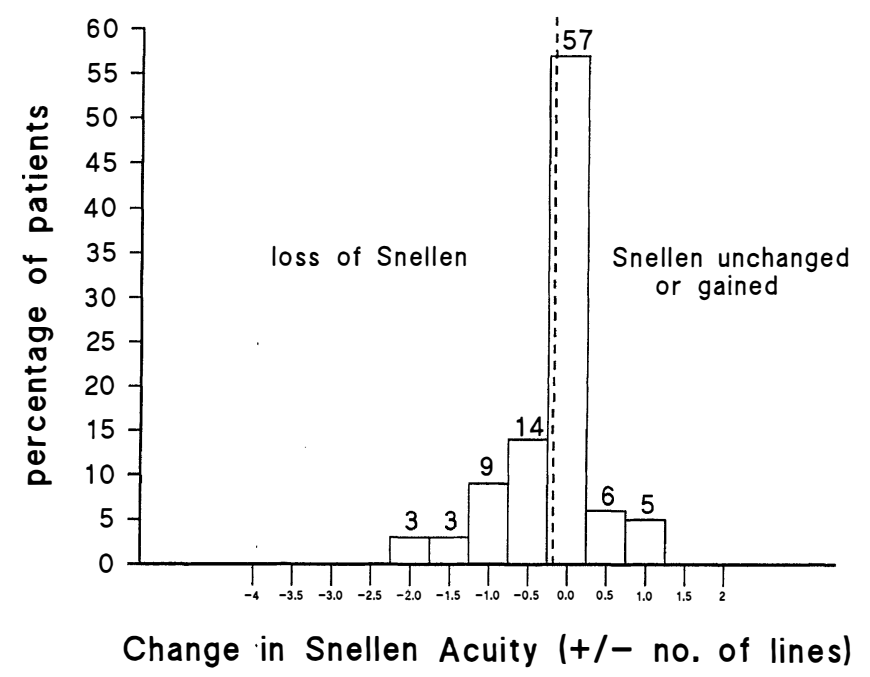

Fig. 4b.

Fig. 4. Histograms showing loss or gain of best spectacle corrected visual acuity (all groups) at 6 months (a) and 1 year (b). The vertical broken line represents the point at which there has been no change in acuity. 
haze and the depth of the induced ablation $(p<0.001)$ and a moderately good correlation between haze and regression $(R=0.75$ on average $){ }^{3}$

\section{Axial Length}

We reported in our previous series that high myopes underwent greater regression and developed greater haze than medium myopes undergoing the same correction. ${ }^{1,2}$ However, there was no relationship between axial length and anterior stromal haze or refractive outcome.

The present study shows that topical corticosteroids have a significant beneficial effect on refraction while used in the first 3 months following excimer laser photorefractive keratectomy. However, beyond 3 months, at which time steroids were discontinued, no statistically significant difference in refraction could be demonstrated. Anterior stromal haze was not influenced by the presence or absence of steroids at any stage. It can be hypothesised that the use of high-dose topical corticosteroids beyond 3 months may sustain the beneficial effect on refraction and minimise regression, but this would be at the expense of side effects from these agents. We conclude, therefore, that topical corticosteroids should not be used following photorefractive keratectomy. Studies are under way to investigate the effects of other agents which may be of use in modulating the wound healing response after this new form of refractive surgery.

We thank the Iris Fund for financial support in relation to both the purchase and maintenance of the laser and the provision of a Research Fellowship for the principal investigator, Mr. Gartry. We also thank Mr. Nick Taub and Mrs. Fiona Warburton of the Department of Public Health Medicine, St. Thomas' Hospital, for their help in the design of this study and statistical analysis. We are also grateful to the pharmacy staff of Moorfields Eye Hospital who supplied and coded the topical preparations and to Summit Technology for technical support. Sister Anne Welch and Mrs. Judith Armstrong gave invaluable clinical assistance for which we are indebted.

Professor Marshall is a consultant for Summit Technology and acknowledges an equity interest in the company. Drs. Gartry and Kerr Muir have no proprietary interest in the subject matter of this paper.

Key words: Corticosteroids, Excimer laser, Myopia, Photoablation, Photorefractive keratectomy (PRK), Regression, Stromal haze, Wound healing.

\section{REFERENCES}

1. Gartry DS, Kerr Muir MG, Marshall J. Photorefractive keratectomy with an argon fluoride excimer laser: a clinical study. Refract Corneal Surg 1991;7:420-35.

2. Gartry DS, Kerr Muir MG, Marshall J. Excimer laser photorefractive keratectomy: 18 month follow-up. Ophthalmology 1992;99:1209-19.

3. Gartry DS, Kerr Muir MG, Lohmann CP, Marshall J. The effect of topical corticosteroids on refractive outcome and corneal haze after photorefractive keratectomy. Arch Ophthalmol 1992;110:944-52.
4. Tuft SJ, Zabel RW, Marshall J. Corneal repair following keratectomy: a comparison between conventional surgery and laser photoablation. Invest Ophthalmol Vis Sci 1989;30:1769-77.

5. Seiler T, Kahle G, Kriegerowski M, Bende T. Myopic excimer laser (193 $\mathrm{nm}$ ) keratomileusis in sighted and blind human eyes. Refract Corneal Surg 1990;6:165-73.

6. Seiler T, Wollensak J. Myopic photorefractive keratectomy with the excimer laser: 1 year follow-up. Ophthalmology 1991;98:1156-63.

7. Liu JC, McDonald MB, Varnell R, Andrade HA. Myopic excimer laser photorefractive keratectomy: an analysis of clinical correlations. Refract Corneal Surg 1990;6:321-8.

8. Zabel RW, Sher NA, Ostrov CS, Parker P, Lindstrom R. Myopic excimer laser keratectomy: a preliminary report. Refract Corneal Surg 1990;6:329-34.

9. Sher NA, Chen V, Bowers RA, Frantz JM, et al. The use of the 193-nm excimer laser for myopic photorefractive keratectomy in sighted eyes: a multicentre study. Arch Ophthalmol 1991;109:1525-30.

10. Gartry DS, Kerr Muir MG, Marshall J. Excimer laser superficial keratectomy: a laboratory and clinical study. $\mathrm{Br} \mathrm{J}$ Ophthalmol 1991;75:258-69.

11. Cox WV, Kupferman A, Leibowitz HM. Topically applied steroids in corneal disease. II. The role of drug vehicle in stromal absorption of dexamethasone. Arch Ophthalmol 1972;88:549-52.

12. Kupferman A, Leibowitz HM. Topically applied steroids in corneal disease. V. Dexamethasone alcohol. Arch Ophthalmol 1974;92:329-30.

13. Leibowitz HM, Stewart RH, Kupferman A, Kimbrough RL. Evaluation of dexamethasone acetate as a topical ophthalmic formulation. Am J Ophthalmol 1978;86:418-23.

14. Fantes EF, Hanna KD, Waring GO, Pouliquen Y, Thompson KP, Salvodelli M. Wound healing after excimer laser keratomileusis (photorefractive keratectomy) in monkeys. Arch Ophthalmol 1990;108:665-75.

15. Hanna KD, Pouliquen YM, Salvodelli M, et al. Corneal wound healing in monkeys 18 months after excimer laser photorefractive keratectomy. Refract Corneal Surg 1990;6:340-5.

16. Sunder Raj N, Geiss MJ, Fantes F, et al. Healing of excimer laser ablated monkey corneas. Arch Ophthalmol 1990;108: 1604-10.

17. Marshall J, Trokel S, Rothery S, Krueger RR. Long-term healing of the central cornea after photorefractive keratectomy using an excimer laser. Ophthalmology 1988;95: 1411-21.

18. Thygeson P. The unfavourable role of corticosteroids in herpetic keratitis. In: Brockhurst RJ, et al. editors. Controversy in ophthalmology. Philadelphia: Saunders, 1977:450.

19. Spaeth GL, Sallman von L. Corticosteroids and cataracts. Int Ophthalmol Clin 1966;6:915-9.

20. Yablonski ME, Burde RM, Kolker AE, Becker B. Cataracts induced by topical dexamethasone in diabetes. Arch Ophthalmol 1978;9:474-9.

21. Lohmann C, Fitzke F, Timberlake G, Gartry DS, Kerr Muir MG, Marshall J. Corneal haze after excimer laser refractive surgery: objective measurements and functional implications. Eur J Ophthalmol 1992;1:173-80.

22. Lohmann C, Fitzke F, Timberlake G, Gartry DS, Kerr Muir MG, Marshall J. Corneal transparency after excimer laser photo-refractive keratectomy: a new technique for objective measurements of haze. Refract Corneal Surg 1992;8: $114-21$. 